\title{
O diagnóstico como "passaporte" para reconhecimento e significação das experiências na dislexia
}

\section{| ${ }^{1}$ Denyse Telles da Cunha Lamego, ${ }^{2}$ Martha Cristina Nunes Moreira |}

Resumo: Analisamos as implicaçôes do diagnóstico de dislexia na produção de sentidos sobre as experiências relacionadas a esta condição, a partir da ótica de diferentes atores sociais em campos de interações diversos. Utilizamos o método de narrativas em diálogo com os conceitos de "normalidade" e "patologia", "ideologia” e "cultura” e com o campo teórico-conceitual da "Sociologia do Diagnóstico". Realizamos 19 entrevistas-narrativas com atores sociais diferentemente posicionados na estrutura social, recrutados a partir da rede social Facebook, no grupo "Dislexia e Pais”. Discutiu-se o contexto sócio-histórico de construção social da categoria diagnóstica "dislexia"; a peregrinação por diagnóstico, barreiras e conflitos encontrados nos sistemas de saúde e educação; a importância do diagnóstico biomédico para a significação da experiência de adoecimento pela dislexia; o papel e as funçóes do diagnóstico de dislexia para a busca de reposicionamentos e reordenamentos da vida cotidiana, para a construção de marcas identitárias, assim como para o reconhecimento e acesso a direitos em espaços públicos. O diagnóstico de dislexia foi interpretado como um personagem principal que apresenta funçóes positivas e negativas na vida cotidiana de pessoas vivendo com essa condição.

> Palavras-chave: dislexia; diagnóstico; sociologia do diagnóstico; narrativas.

\author{
${ }^{1}$ Ambulatório de Fonoaudiologia \\ Especializado em Linguagem, \\ Instituto Fernandes Figueira, \\ Fundação Oswaldo Cruz. Rio \\ de Janeiro-RJ, Brasil (denyse. \\ lamego@gmail.com). \\ ORCID: 0000-0003-3642-4465 \\ ${ }^{2}$ Coordenação de Ensino, \\ Instituto Fernandes Figueira \\ Fundação Oswaldo Cruz. \\ Rio de Janeiro-RJ, Brasil \\ (marthacnmoreira@gmail.com). \\ ORCID: 0000-0002-7199-3797
}

Recebido em: 21/01/2019

Revisado em: 06/05/2019

Aprovado em: 25/05/2019 


\section{Introdução}

A dislexia localiza-se na fronteira da saúde e da educação, espaços institucionais cuja interação é marcada por conflitos e divergências, resultados de múltiplos discursos e ideologias em contextos sócio-históricos específicos. Enquanto categoria diagnóstica do campo biomédico, apresenta uma base neurobiológica primária, que caracteriza um padrão "desviante" de funcionamento para a leitura em relaçáo a uma norma arbitrariamente aceita. Essa condição se expressa de diferentes formas e graus de severidade, de modo persistente e durável, acompanhando o sujeito ao logo de toda a vida (LYON; SHAYWITZ; SHAYWITZ, 2003; SANTOS; NAVAS, 2016). Configura-se como uma experiência de adoecimento crônico (CANESQUI, 2015; 2018; BARSAGLINI, 2013; FLEISCHER; FRANCH, 2015; CASTELLANOS, 2011), já que deflagra a busca por condiçóes de restabelecimento de certa "normalidade" e de inserção e adaptação ao meio social (CANGUILHEM, 2009).

No campo particular de interaçôes e cuidados que envolvem a dislexia, diferentes atores sociais são confrontados cotidianamente com o sofrimento, dadas as limitaçôes relacionadas a este "distúrbio". Nas queixas dos pais e nos encaminhamentos de profissionais de saúde ou das escolas observam-se os estereótipos de "criançasproblema", "que não aprendem", "que não evoluem", "que não acompanham", assim como os de "déficit", "deficiência", "atrasos". Essas marcas as localizam, hierarquicamente, no universo da falha, do fracasso e da (in)diferença, e cursam, muitas vezes, com relatos de exclusão e inadaptação social, escolar e profissional.

A linguagem é definida como uma habilidade humana fundamental para a construção das relaçôes intersubjetivas e para as aprendizagens (MOUSINHO et al., 2008) e é estratégica para o desenvolvimento humano, especialmente quanto às exigências do mundo social e produtivo contemporâneo (LAW; REILLY; SNOW, 2013). Desta forma, problemas específicos de linguagem e aprendizagem começam a ser apontados como uma nova questão de saúde pública, que requerem monitoramento, investigação, diagnóstico diferencial e abordagem preventiva e precoce, visando à reduçâo de iniquidades (DOCKRELL et al., 2014; LAW; REILLY; SNOW, 2013; HARTSHORNE et al., 2006).

Segundo Thompson (2009), o campo de interação entre o sujeito e as instituições sociais no curso da vida cotidiana é constantemente atravessado pela produção e difusão de valores e crenças mais ou menos apreciados em um dado contexto sócio- 
histórico e pelo plano ideológico que organiza as instituiçôes sociais. Essas relaçôes são hierarquicamente estabelecidas, marcadas por assimetrias sistemáticas, estáveis e duráveis que influenciam a distribuição e o acesso a recursos, assim como nas oportunidades e chances de vida. A experiência de adoecimento pela dislexia, nas interfaces com o campo institucional, suas normas e convenções, é produtora de sofrimento, conflitos, marcas identitárias e estigmas (MOREIRA; SOUZA, 2002; MOREIRA; MACEDO, 2003). E mobiliza diferentes ações no conjunto das relaçôes sociais, frente à dinâmica de seu enfrentamento e às necessidades de cuidado e/ou adaptação em campos de interação normatizados.

Neste artigo, analisamos os sentidos do diagnóstico de dislexia, tomado como objeto de investigação sociológica (JUTEL, 2011; 2009; ROSENBERG, 2002), e suas repercussốes na vida cotidiana de sujeitos em diferentes fases do curso da vida e em campos de interação social diversos. Essas discussões iluminam a compreensão da construção social desta categoria diagnóstica, do processo de medicalização das experiências de ensino-aprendizagem e dos sentidos sociais do viver com dislexia.

A expressão "passaporte" não configura aqui uma categoria êmica - mas sim uma categoria analítica, resultante da interpretação das autoras sobre o acervo de pesquisa - e é utilizada como forma de representar justificativas, autorizaçóes, estratégias e possibilidades de pessoas - crianças, adolescentes, jovens e adultos - serem inseridas em espaços públicos de cuidado, ensino, trabalho e sociabilidade.

\section{Metodologia}

Este estudo integra uma pesquisa mais abrangente, que investigou narrativas de diferentes atores organizados a partir de ambiente virtual, com vistas a analisar como enunciam e representam os problemas do desenvolvimento da linguagem e aprendizagem, e como reivindicam e evocam suas necessidades em espaços públicos. Destacamos que o ambiente virtual náo se configurou como um universo de pesquisa, no sentido de apresentar-se como um lócus de relações, práticas e interaçôes a serem observadas, de caráter etnográfico. Ele foi o ponto de partida para um convite feito a pessoas cujo diagnóstico de dislexia era um mediador privilegiado para organização identitária, de uma experiência "em comum".

A categoria diagnóstica "dislexia" foi escolhida pelo fato de:

a) sujeitos com essa condição constituírem grupos localizados num intervalo da atenção, não sendo devidamente contemplados no escopo das políticas públicas; 
b) ser uma categoria diagnóstica que alcançou certo grau de problematização e mobilização na busca por reconhecimento e visibilidade, constatando-se a existência de associaçôes (Associação Nacional de Dislexia e Associação Brasileira de Dislexia) e de projeto de lei (BRASIL, 2010).

A construção do campo da pesquisa inspirou-se em estudos que pautam os ambientes virtuais como campos privilegiados para investigaçóes no campo das Ciências Sociais e Humanas (SÃO BENTO, 2016; PEREIRA NETO et al., 2015), onde determinadas pessoas buscam outras pelo que pode haver em comum, no encontro com pares, apoios, informações. Nessa direção, o grupo "Dislexia e Pais", situado na rede social Facebook, serviu exclusivamente ao recrutamento dos sujeitos do estudo, a fim de participarem de uma entrevista-narrativa. Trata-se de um grupo com mais de seis mil participantes, dedicado à divulgação e fornecimento de suporte e esclarecimentos sobre a dislexia. Este grupo foi selecionado por ser um lugar de encontro de diferentes atores sociais que partilhavam algum grau de organização e mobilização social e política em torno da problemática comum sob investigação, e com possibilidades de evocar suas percepçôes e experiências a partir de referenciais de saberes leigos e formais.

O acesso ao grupo "Dislexia e Pais" foi realizado mediante autorização dos administradores da página. Este acesso em um ambiente virtual exigiu a adoção de estratégias para o estabelecimento de uma relação de confiança entre o pesquisador e o campo-sujeitos da investigação, fundamentais aos processos de negociação, avaliação das intençôes, apresentação da pesquisa e minimização de riscos (SÃO BENTO, 2016). Foram oferecidos símbolos de segurança em relação à identidade da pesquisadora, às intençôes do estudo e referências institucionais, através de cartaconvite, sumário da pesquisa, e-mail e telefone institucionais e links para currículos Lattes. A pesquisa foi aprovada por Comitê de Ética em Pesquisa (CEP) através dos pareceres no 1.634 .640 e n 1.735 .833 .

Os participantes foram recrutados a partir de três fontes: indicações do administrador do grupo virtual de membros considerados estratégicos; aceites espontâneos via comentários ou mensagens privadas, a partir da divulgação da pesquisa na página do grupo; membros do grupo vinculados à rede de relaçôes da pesquisadora. $\mathrm{O}$ recrutamento subsequente de novos participantes valeu-se da técnica de Universos Familiares (VELHO, 1978). Os interesses pessoal e político 
em relação à investigação proposta foram os principais elementos mobilizadores para a configuração final do universo da pesquisa. Foram incluídos sujeitos com idade acima de 18 anos e diagnóstico de dislexia do participante ou do filho (a) fornecido por médico ou equipe multidisciplinar. Dificuldades na linguagem/aprendizagem secundárias a outros transtornos foram critérios de exclusão.

O trabalho de campo durou seis meses - agosto/2016 a janeiro/2017 -, ao longo dos quais foram realizadas dez postagens de divulgação da pesquisa no grupo virtual, desde o momento da aprovação pelo Comitê de Ética em Pesquisa e a autorização do administrador do grupo. $\mathrm{O}$ universo da pesquisa foi definido por critérios de amostra qualitativa e o momento de interrupção das entrevistas seguiu a exigência de variação e saturação teórica (MINAYO, 2014).

Foram entrevistados 19 participantes em sete cenários: Casimiro de AbreuRJ, São Paulo-SP, São José do Rio Preto-SP, São Vicente-SP, Curitiba-PR, Rio de Janeiro-RJ e Salvador-BA. As entrevistas foram conduzidas presencialmente, em espaços públicos, ou à distância, através de webconferência, gravadas e transcritas. Das narrativas emergiram 43 enunciados que foram organizados em três dimensóes, microanalítica (experiência pessoal), mesoanalítica (campo de interação institucional) e macroanalítica (político-propositiva). O "diagnóstico de Dislexia" surgiu como eixo central que organizou três núcleos narrativos resultantes da interação dinâmica das dimensões identificadas.

Neste artigo, analisamos o núcleo narrativo que examinou o diagnóstico de dislexia como uma "forma simbólica" (THOMPSON, 2009) para o reconhecimento e significação da experiência de adoecimento. $O$ método de narrativas (CASTELLANOS, 2014; MUYLAERT et al., 2014; JOVCHELOVITCH; BAUER, 2003) fundamentou a análise e interpretação dos eventos, personagens, enredos, nexos e ancoragem cultural de aspectos particulares, mas que apresentaram traços comuns no conjunto das narrativas. Os sujeitos de pesquisa foram mães de crianças, adolescentes ou jovens com dislexia (M); mães com dislexia (MD); jovens (JD) e adultos (AD) com dislexia; profissionais de saúde (PS); profissionais de educação (PE). Esses códigos foram antecedidos da letra E (entrevistado), seguida do número sequencial de realização das entrevistas, a fim de assegurar o anonimato dos sujeitos.

No escopo da análise formal ou discursiva, examinaram-se aspectos estruturais nos enunciados dos participantes frente a essas experiências, além dos códigos com regularidades de significação intrínsecas, que emergem e circulam nos campos sociais 
com infinitas possibilidades de expressão. A interpretação dos resultados baseouse no diálogo com os conceitos de "ideologia" e "cultura" (THOMPSON, 2009), "normalidade" e "patologia" (CANGUILHEM, 2009) e no referencial da Sociologia do Diagnóstico (JUTEL, 2011; 2009; ROSENBERG, 2002), a fim de desvelar aspectos das condiçôes sociais e históricas na conformação de formas simbólicas ligadas às experiências com a dislexia, suas condiçôes sociais e culturais de produção e recepção e as relaçôes de poder nos campos de interação em que se situam.

O quadro abaixo sintetiza o método e os elementos centrais que orientaram a análise dos resultados e a interpretação dos conteúdos narrativos (adaptado de MOREIRA et al., 2014).

Quadro 1. Etapas do método de Narrativas com a síntese dos principais achados e caminhos interpretativos

\begin{tabular}{|c|c|c|}
\hline \multicolumn{3}{|c|}{ ANÁLISE NARRATIVA } \\
\hline \multicolumn{3}{|c|}{ Análise sócio-histórica } \\
\hline Situaçóes espaço-temporais & Campos de interação & Nível institucional \\
\hline $\begin{array}{c}\text { - Fracassos na aprendizagem } \\
\text { - Rupturas entre a norma } \\
\text { vital e as normas sociais e } \\
\text { institucionais } \\
\text { - Inadaptação, rótulos e } \\
\text { estigmas }\end{array}$ & $\begin{array}{c}\text { - Saber médico X saber leigo } \\
\text { - Relaçóes assimétricas de } \\
\text { poder e dominação }\end{array}$ & $\begin{array}{l}\text { - Normas e hierarquias } \\
\text { institucionais (serviços de } \\
\text { saúde e educacionais) } \\
\text { - Dificuldades no acesso } \\
\text { a profissionais e serviços } \\
\text { especializados }\end{array}$ \\
\hline \multicolumn{3}{|c|}{ Análise narrativa do discurso } \\
\hline Personagens e Eventos & Enredos e Nexos & Ancoragem cultural \\
\hline $\begin{array}{c}\text { - Diagnóstico de dislexia } \\
\text { • Laudo médico } \\
\text { - Sentidos e funçóes do } \\
\text { diagnóstico }\end{array}$ & $\begin{array}{l}\text { • Peregrinação por } \\
\text { diagnóstico e tratamento: } \\
\text { itinerários terapêuticos } \\
\text { - Trajetórias pessoais } \\
\text { e familiares de (re) } \\
\text { significação da experiência } \\
\text { de adoecimento e (re) } \\
\text { direcionamentos da vida }\end{array}$ & $\begin{array}{l}\text { - Valor social da leitura- } \\
\text { escrita em diferentes } \\
\text { momentos sócio-históricos } \\
\text { - Posicionamentos do } \\
\text { indivíduo na sociedade: } \\
\text { exerce influência sobre } \\
\text { as oportunidades e } \\
\text { possibilidades de realização }\end{array}$ \\
\hline
\end{tabular}




\begin{tabular}{|c|}
\hline Síntese interpretativa \\
\hline • Conformação da experiência de saúde-doença-adoecimento na dislexia \\
• Diagnóstico como "passaporte" para ressignificação das experiências de fracasso e \\
adoecimento \\
- Diagnósticos como expressão da autoridade médica e como expressão cultural do que a \\
sociedade demanda ser tratado \\
- Diagnóstico como "passaporte" para acesso a serviços, construção de identidades coletivas \\
e mobilização de políticas públicas de saúde e educacionais
\end{tabular}

Fonte: elaboração própria, a partir de Lamego (2018).

\section{Resultados e Discussão}

As dificuldades do domínio da aprendizagem começam a ganhar o estatuto de "problema" a partir da inserção da criança no ambiente escolar, no confronto com as exigências da aprendizagem formal. $O$ fato de não aprender se configura como uma experiência que desaloja o sujeito da relação entre a sua norma vital e aquela socialmente esperada, provocando uma ruptura no curso aparentemente "normal" da vida. O insucesso da criança nos períodos iniciais da aprendizagem da leitura-escrita coloca em evidência certos padrôes de comportamento humano que, por expressarem modos diferentes ou desviantes de uma norma comumente observada, são percebidos como problemas concretos, que passam a ser nomeados como "sintomas" e evocam a necessidade de intervenção (CANGUILHEM, 2009). É na conjuntura do conflito entre as preocupaçôes e sintomas identificados pela família, os fracassos da criança diante do aprendizado e as referências normativas da escola que a experiência de adoecimento se instala, entendida como aquilo que rompe com o silêncio entre o sujeito e seu próprio corpo, e faz com que a dificuldade em aprender adquira o estatuto de "doença" (CANGUILHEM, 2009).

O diagnóstico desempenha, então, um papel estruturante na experiência do sujeito, pois demarca a linha divisória entre o normal e o anormal, e influencia diretamente a comunicação e estruturação dos relacionamentos sociais que envolvem as experiências de adoecimento (JUTEL, 2011). Assim, a experiência de fracasso diante das exigências normativas da instituição escolar em relação às aprendizagens, que culmina com rótulos sociais como "desatento", "desobediente", "lento", entre outros, passa a encontrar, no território da medicina e das classificaçóes médicas, um outro campo de nomeaçáo e interposição de rótulos e normatividades, porém, 
capazes de fornecer uma explicação plausível para prover respostas ao indivíduo frente às demandas sociais igualmente normatizadas. O diagnóstico funciona, então, como um rótulo, uma categoria real que nomeia uma constelação de queixas e as experiências de adoecimento, e permite ao sujeito ressignificá-las e reordená-las em direção à busca de estratégias de enfrentamento (JUTEL, 2009).

As narrativas de experiências com a dislexia trazem à tona diferentes áreas de tensão, como o processo de peregrinação por diagnóstico, onde o mesmo representa um "passaporte" para justificar a diferença e reivindicar o direito de ser cuidado e de estar presente em espaços sociais como a escola. Isso, com base no pressuposto de que o saber médico sobre a doença e a eficácia terapêutica são, a priori, suficientes para combater o sofrimento, restabelecer a saúde e validar dispositivos clínicos (SAFATLE, 2011). Como relatam as mães E15 e E5, "a gente fica desesperada [...] vê aquela criança sofrendo"; "a gente sofre muito, porque às vezes a gente não acha uma ajuda assim... pra tratar dos nossos filhos".

Essa peregrinação - que implica menos em acesso e mais em barreiras, sofrimento, atribuiçôes de estereótipos - pode ser interpretada como característica de um itinerário terapêutico vinculado às buscas de cuidado para pessoas com diagnósticos onde residem altos graus de dissenso sobre sua identificação e/ou localização nos campos de conhecimento. Como nos lembra Alves (2015, p. 30):

O itinerário terapêutico (IT) é um dos conceitos centrais nos estudos socioantropológicos da saúde. Trata-se de um termo utilizado para designar as atividades desenvolvidas pelos indivíduos na busca de tratamento para a doença ou aflição.

Essas atividades de busca de cuidados dialogam com diversas barreiras, que incluem os significados do adoecimento para o doente, sua configuração diagnóstica para os especialistas, as interpretaçôes de quem convive com o doente e suas interaçôes institucionais. Segundo Gerhardt (2006, p. 2462): “Os itinerários terapêuticos dependem de estratégias complexas fundamentadas na elaboração de relaçôes sociais e de práticas de inserção social”. Conectando-se ao presente estudo, considerando-se o alto grau de dissenso em torno da capacidade de "fechar o diagnóstico", compreender causalidades que escapam ao modelo estritamente biomédico, e precisam de articulaçôes com áreas da educação, avaliação de linguagem, por exemplo, o enredamento do itinerário se torna complexo, revelandose em "peregrinação": "agora com 13 anos é que tá fazendo a terapia" (E5-M); "quando fechou o diagnóstico [...] já tava com 9 anos [...] então ele foi se arrastando 
na escola todo esse tempo, sem ter um atendimento diferenciado [...] e sem a gente ter uma... orientação" (E20-M).

Nas narrativas, a busca por diagnóstico revelou-se um grande desafio, e apontou as dificuldades relacionadas à falta de profissionais disponíveis e capacitados e a restrição no acesso aos serviços de saúde, devido à distância geográfica ou à falta de serviços especializados para diagnóstico de crianças, adolescentes e adultos. Essa busca é narrada como algo interminável e difícil: "correr de um lado para o outro" (E3-M); "nós estamos distantes" (E6-MD); "levei em vários" (E17-MD); "foi muito difícil" (E20-M); "passei por profissionais horríveis" (E15-M); "eu tive que pagar caro pra que fizesse [...] a avaliação comigo, eles [...] foram se adaptar, porque [...] não fazem diagnóstico com adulto" (E16-AD). Ao mesmo tempo que o diagnóstico é buscado e desejado, o itinerário percorrido até alcançá-lo revela-se uma experiência desestruturante para crianças e famílias, mobilizando múltiplos sentimentos e emoçôes, como "revolta" e "ansiedade" - "fiquei revoltada", "foi um desgaste muito grande" (E17-MD); "eu me desestruturei completamente" (E20-M).

As dificuldades no acesso ao diagnóstico revelaram as limitaçóes do sistema de saúde para atendimento às demandas, evidenciaram as barreiras enfrentadas no interior desse sistema e o confronto das famílias com a carência de serviços e de profissionais qualificados para o diagnóstico. Nos itinerários terapêuticos realizados pelos participantes na busca por diagnóstico e tratamento, vê-se que a dislexia apresenta como especificidade o fato de ser persistente, necessitar de intervençóes terapêuticas de longa duração e mobilizar a atuação de equipes multiprofissionais. Isto aponta para a necessidade de se empreender um novo olhar sobre as práticas em saúde relacionadas a condiçóes crônicas em crianças e adolescentes, com reorientação de serviços de saúde, formação e capacitação de profissionais, e investimentos para reformulação deste campo de produção de cuidado (MOREIRA; CUNHA; MELLO, 2016).

A peregrinação por diagnóstico remete a um rol de significados que evocam a dimensão pessoal da experiência com a dislexia enquanto uma condição crônica que, por sua complexidade, mobiliza mudanças nas relaçôes e trajetórias familiares. Castellanos (2011) observa que essa busca - no caso de crianças com uma condição crônica de saúde pouco conhecida, a fibrose cística - pode ser interpretada como um processo que faz emergir múltiplas significaçôes sobre as experiências no âmbito das negociaçóes entre crianças, famílias e profissionais. 
A literatura sobre cronicidade e adoecimento crônico - que subsidia a discussão anterior, e recorre a revisóes nacionais e internacionais - analisada por diversos autores (CANESQUI, 2015; 2018; BARSAGLINI, 2013; FLEISCHER; FRANCH, 2015), nos possibilita alcançar a experiência como categoria relacional e interacional, onde sofrimento, busca por tratamento, geração de significados e respostas dialogam com o conhecimento biomédico, mas não se reduzem aos mesmos, no campo da cronicidade.

Jutel (2009) afirma que o diagnóstico médico é, portanto, muito desejado, pois ele detém o poder de transformar um sintoma, uma queixa ou um rótulo social em doença. Permite ao sujeito encarnar a doença e viver a experiência de adoecimento através dela, e fornece uma explicação ou isenção para aquilo que o torna diferente ou desviante em relação à norma que prevalece em um determinado campo de interação social.

A perspectiva do diagnóstico de dislexia como algo que não tem cura foi relatada por mães e jovens como uma "notícia difícil" - "é um diagnóstico pesado [...] pro resto da vida!" (E8-M) - ou como algo que teve impacto de "doença” e de "defeito" - "parece que tá dando uma notícia que a pessoa tá morrendo [...] Tem cura isso? Tem conserto?” (E11-JD).

A categoria "gravidade" conjugada ao atributo "incurável" constitui um importante parâmetro para dimensionar problemas crônicos de saúde e seus impactos na vida familiar e individual. Para Castellanos (2011), essas características colocam em cena valores e concepçóes dos indivíduos e suas redes de interação social que, confrontados com os conceitos formulados por profissionais, serviços e pela própria sociedade, acarretam sentimentos de desestabilização e incertezas, e colocam em jogo as expectativas para a vida. A cronicidade em processos de adoecimento infantil torna a dimensão da temporalidade ainda mais complexa, considerando-se que a criança é um ser em desenvolvimento e, socialmente, dimensionada em seu devir. Assim, é natural que se projete sobre ela um conjunto de possibilidades e expectativas presentes e futuras, relacionadas à sua própria trajetória e à de seus pais/ familiares (CASTELLANOS, 2011; CORSARO, 2011).

A experiência da dislexia rompe com a normatividade que rege as práticas sociais. Nas situaçóes enfrentadas, as referências de normatividade atuam sobre os posicionamentos, sentimentos, expectativas e identidades no curso da vida. Produzem movimentos de ruptura e estabilização que podem ser compreendidos a partir das categorias "situações normais" e "situaçôes-limite" (CASTELLANOS, 
2011, p. 37). Estas remetem às ideias de estabilidade, permanência e continuidade nas atividades humanas ou de rupturas e crises que determinam mudanças por perda de marcos de referência. Os sentidos de gravidade e cronicidade da doença presente nos jogos simbólicos produzidos em torno da dislexia, que são enunciados no momento da notícia do diagnóstico, foram expressos pelos participantes através da evocação de dois sentimentos antagônicos: o de "apreensão", quando associado a angústias e expectativas quanto à inserção do indivíduo no meio social; e o de "alívio", quando relacionado às possibilidades de nomeaçáo, compreensão e significação proporcionadas pelo diagnóstico.

Segundo Thompson (2009), as relaçóes sociais e posicionamentos se organizam a partir de valores e crenças em um determinado contexto sócio-histórico. As expectativas e o julgamento social revelam o valor simbólico atribuído pela sociedade ao aprendizado da leitura/escrita. Isto mobiliza um forte impacto ao diagnóstico de dislexia: sobre a criança recaem expectativas e sobre os pais, a responsabilização e a necessidade de agir, como enuncia E6-MD: "quando você recebe essa notícia, não é fácil, porque [...] a sociedade cobra algumas coisas [...] é praxe, né, todo mundo tem que fazer".

O aprendizado da leitura e da escrita constitui um importante mecanismo de controle da sociedade, e o seu êxito ou fracasso pode ser determinante das vantagens ou desvantagens que a criança irá dispor para a construção de cidadania e inserção social (MORTATTI, 2010). Desta forma, elementos de ordem conjuntural da vida convertem-se em diferenças coletivas e duráveis, e se traduzem em um conjunto estável de manifestaçóes que interferem diretamente na distribuição e acesso a recursos, poder, oportunidades e possibilidades de realização (THOMPSON, 2009).

O efeito disruptivo do diagnóstico foi assim enunciado: "Poxa, meu filho não vai aprender a ler e escrever? [...] como que ele vai se virar num mundo escrito? [...] como que ele vai tirar "carta"? [carteira de motorista] [...] E agora? O que que eu vou fazer?" (E6-MD). Para E8-M, apesar de ser um diagnóstico "definitivo" e "pesado", essa descoberta pode representar um "alívio", pois é a partir dele que se pode ajudar. A experiência do jovem com dislexia E18-JD enseja a descoberta do diagnóstico como "uma guerra e um alívio ao mesmo tempo, porque você sabe que você não é mais retardado, que você tem alguma coisa que tem nome". Poder nomear o problema abre a possibilidade de pesquisar e buscar caminhos para "solucionar ou suavizar a dislexia. Então, isso é um alívio”. 
Assim, da instabilidade inicial produzida pelo diagnóstico, chega-se, gradativamente, a possibilidades de reorganização, que levam a um novo equilíbrio (CASTELLANOS, 2011; BARSAGLINI, 2013), aproximando-nos da definição de saúde apresentada por Canguilhem (2009, p. 77) - a "possibilidade de ultrapassar a norma que define o normal momentâneo, [...] de tolerar infraçôes à norma habitual e de instituir normas novas em situaçóes novas".

Validar o sofrimento gera alívio e funciona como algo capaz de trazer maior concretude ao problema (JUTEL, 2009). Essa materialidade possibilita ao indivíduo um reposicionamento da sua identidade social (GOFFMAN, 2004) e o auxilia no processo de elaboração subjetiva da sua própria condição para, entáo, encontrar caminhos de normalização da experiência. Aqui, cabe destacar pesquisas com crianças e adolescentes que desde o nascimento vivem com a condição de adoecimento crônico, onde não se coloca um antes e um depois em suas vidas (CASTELLANOS, 2011; MOREIRA, 2015; PROTUDJER et al., 2009; WILLIAMS et al., 2009), mas uma trajetória de normalização da experiência, que será significada se os adultos de referência conseguirem também enfrentar rupturas de rotinas e expectativas, e ressignificarem essa experiência, normalizando-a. Um jovem com dislexia destaca o diagnóstico e o suporte que recebeu da família como decisivos - "então, se tornou tão normal as coisas [...] hoje em dia [...] eu não lembro que eu tenho dislexia" (E18). Contraditoriamente, a falta de suporte e de sentido para lidar com a incapacidade de aprender e com os fracassos vivenciados a partir dessa situação foram referidos como produtores de marcas traumáticas: "Se eu que não conseguia e todo mundo consegue, a burra sou eu [...] a vivência que eu tenho disso foi muito traumática pra mim" (E19-AD).

Outra ponderação dos participantes destaca o papel, a responsabilidade e o poder que cabe aos pais de cuidar e decidir sobre a vida dos filhos. Assim, diante de posicionamentos profissionais e/ou sociais que naturalizam as dificuldades da criança e desqualificam as inquietaçôes dos pais ao afirmarem que "não há nenhum problema”, mas que cobram desempenhos normatizados e julgam diferenças, não buscar o diagnóstico foi referido como uma "fraqueza" ou "acomodação". Em contrapartida, buscar o diagnóstico é apresentado como um dever dos responsáveis: "a gente tem o direito de fazer isso [não buscar o diagnóstico] quando a consequência tá na nossa vida. Agora, quando a pessoa depende da gente [...] se a gente fizer tudo o que a gente acha que pode fazer e errar lá na frente, mas pelo menos a gente fez 
tentando acertar" (E8-M); "eu quero um filho com capacidade de sobreviver no mundo [...] eu quero dar a ele a oportunidade dele ter uma vida digna. E isso vai depender de mim, ele é uma criança" (E6-MD).

Ilumina-se, assim, o exercício de poder e dominação existente nas relaçóes estabelecidas entre os atores diferentemente posicionados na estrutura social (THOMSPON, 2009; CAPRARA; RODRIGUES, 2004). De um lado, o poder das falas de profissionais que, ao acionarem sua autoridade e argumentos sustentados por conhecimentos e racionalidades científicas, terminam por desqualificar e neutralizar as inquietaçóes dos pais. De outro, os pais e mães que, a partir de suas percepçôes, experiências e visōes de mundo, realizam um esforço de questionar tais posicionamentos, sustentar a relação de conflito e poder instaurada nesse campo de interação hierarquizado, e lutam para reduzir assimetrias e assegurar reconhecimento para as dificuldades de seus filhos.

Castellanos (2011) aponta que a experiência da doença pode ser vivida com radicalidade e de forma dilacerante da existência pessoal. Para aqueles que foram diagnosticados somente na idade adulta, nomear a experiência a partir do rótulo médico adquiriu um sentido de grande importância para a reorganização e redirecionamento da vida. A participante E16-AD, que foi diagnosticada aos 38 anos de idade, descreve sua experiência devastadora desde a infância até a vida adulta, onde, a partir do diagnóstico, passou a entender suas limitaçōes e a identificar formas de transpor suas dificuldades:

[...] saber o que eu tinha me trouxe [...] emocionalmente, algo que eu fui compreendida, eu não era burra, eu sabia o que eu tinha [...] só depois do diagnóstico foi que a minha vida começou a funcionar [...] então por isso que eu chamo de divisor [...] e aí eu comecei a viver $[. .$.$] e consegui me enquadrar na sociedade.$

Para E19-AD, a experiência não nomeada revelou-se traumática, desvelando seus profundos sentimentos de fracasso e menos-valia diante de falas da professora: "Sua burra, você não sabe ler! [...] Gente burra póe o dedo pra ler! Gente burra põe uma régua pra ler!' [...] isso pra mim foi muito marcado [...] eu era muito muito triste". No seu caso, receber o diagnóstico aos 39 anos representou a possibilidade de se aceitar mais, minorar seu sofrimento, resgatar sua autoestima e, paulatinamente, modificar uma situaçáo na qual se sentia aprisionada - "Eu posso ser "normal”[...] antes [...] eu ficava me matando, tentando aprender [...] hoje eu tô conseguindo me libertar disso". 
$\mathrm{Na}$ dimensão pessoal, experiências de adoecimento vividas em sua radicalidade podem afetar centralmente a existência, conduzir à revisão dos projetos de vida e requerer mobilização individual ou da rede familiar e social. O diagnóstico pode, então, conduzir a um "processo de normalização" (CASTELLANOS, 2011, p. 38), ao assumir esse caráter de reorganizador e aportar o efeito de estabilização do cotidiano, fundamental à continuidade dos processos da vida e à diminuição do sofrimento.

O diagnóstico pode ser definido como um processo pelo qual se busca um método de avaliação, um olhar organizado e sistematizado sobre determinado sintoma (JUTEL, 2011). A partir do diagnóstico, organiza-se a doença, identificam-se as opçóes de tratamento, pode-se predizer resultados e fornecer quadros explicativos. $\mathrm{Na}$ visão de E9-PS, o diagnóstico tem a função principal de posicionar o indivíduo diante dos desafios da vida: "o diagnóstico não salva e nem condena ninguém, ele só posiciona [...] a pessoa tem que estar muito bem preparada para enfrentar aquela dificuldade”.

Apesar do temor e da hesitação dos pais, essa função do diagnóstico alcança sentidos além daqueles propiciados à experiência pessoal de adoecimento, pois ele permite orientar as ações e os futuros encaminhamentos: "se você tem o diagnóstico, você vai atrás de uma forma específica” (E9-PS). Este sentido do diagnóstico médico, como um orientador das açôes, é corroborado pelas mães, que situam a falta do diagnóstico como um "vazio de compreensão" sobre o que se passa com a criança e de "imobilidade" em relação às medidas a serem tomadas para o enfrentamento do problema - "você tem um norte, você consegue saber o que fazer" (E20-M); "Quando a gente sabe quem é o nosso inimigo, a gente enfrenta" (E8-M).

O diagnóstico assume um estatuto ainda mais importante na relação da família com a escola, pois funciona como "moeda" para reivindicaçôes de acesso a recursos, permitindo a inserção do indivíduo no campo dos direitos: "é importantíssimo esse diagnóstico pra saber o que essa criança tem, pra escola poder tratar direitinho [...] muitas escolas falam: 'sem o diagnóstico, eu não posso saber...” (E7-PS).

O laudo médico é referido como um elemento fundamental, que adquire o estatuto de "personagem principal" nas narrativas. Funciona como um modo de comunicação e como um mecanismo de estruturação das interaçôes burocráticas no âmbito das instituiçôes e suas regras (ROSENBERG, 2002). Para Jutel (2009), o diagnóstico é considerado uma importante ferramenta de delimitação da autoridade médica, nos níveis individual e institucional. Legitima a doença, ao prover significados para queixas e comportamentos socialmente recusados, e oferece uma base formal e 
objetiva capaz de assegurar acesso a direitos, privilégios e/ou condiçôes diferenciadas de tratamento em diferentes contextos sociais, como na escola e no trabalho.

O laudo médico e interdisciplinar atesta a doença e indica a sua gravidade - "o laudo fechou, dislexia... grave" (E3-M); atesta as necessidades do indivíduo quanto a tratamentos especializados; autoriza o acesso a serviços, suportes educacionais e direitos; minora sofrimentos; minimiza diferenças e promove a inclusão social. No caso da dislexia, o laudo fornece informaçôes como o tipo e tamanho de letra mais bem adaptados ao aluno: "vêm todas as indicações [...] toda a instrução pra escola" (E3-M). Permite acessar dispositivos de suporte à aprendizagem, como "tempo extra para a realizaçáo de provas" (E8-M), o direito a fazer "provas orais" e o acesso a "condiçôes diferenciadas": "eles têm a média reduzida na escola, toda criança que tem laudo [...] a média é 5,0" (E20-M). Para jovens e adultos com dislexia, o laudo médico é fundamental para o acesso a "condições especiais em concursos" (E11-JD; E19-AD), como presença de ledor e transcritor. É nesse sentido que o diagnóstico pode ser interpretado como um "passaporte" que justifica a marca da diferença e autoriza a participação do sujeito em espaços públicos. Atestar a doença através do laudo - dispositivo reconhecido e apropriado socialmente - pode representar um meio de o indivíduo tornar-se um participante ativo de diferentes culturas de pares (CORSARO, 2011) até então inacessíveis, sendo determinante para a integração do indivíduo à sociedade e à cultura.

Entretanto, as marcas da diferença continuam presentes, revelando a face contraditória e excludente desses mesmos mecanismos de inclusão, onde estudantes com dislexia são integrados aos espaços convencionais de educação, porém em "salas separadas" (E3-M; E5-M), ou têm os diagnósticos "questionados" -"Olha, professora, eu tenho dislexia' [...], a professora olhava pra mim e dava uma risadinha de canto e... falava "Você tá de sacanagem comigo, né?"' (E18-JD); ou tidos como "privilégios" "Se eu tivesse essa prova fácil, eu tirava dez! E isso é muito injusto!" (E8-M).

O diagnóstico pode ser também interpretado como um julgamento de valor de alguém que detém autoridade e reconhecimento social sobre determinada queixa que uma sociedade considera relevante em um determinado momento e contexto sócio-histórico. Deste modo, os rótulos diagnósticos são importantes, pois servem para demonstrar a emergência de entidades de doenças e como essas abarcam valores sociais e culturais (JUTEL, 2009). Assim, desvios de valor social negativo podem ser nomeados e explicados a partir de rótulos diagnósticos, que passam a fornecer 
uma expressão cultural do que a sociedade está preparada para aceitar como normal e o que ela sente que deve ser tratado (CANGUILHEM, 2009).

A autoridade em medicina se expressa através do direito de definir a saúde e tratar a doença, o que confere ao médico e à medicina uma alta estima pública e uma posição proeminente na hierarquia de competência para o diagnóstico biomédico, traduzida em legitimidade para exercer sua autoridade sobre outros profissionais de saúde e o público leigo (JUTEL, 2011; 2009). O diagnóstico reforça, pois, a autoridade médica e sustenta a profissão médica em seu status de ofício honrado e poderoso, mas também responde a uma demanda social de enquadramento e organização.

O diagnóstico como expressão da autoridade médica e como instrumento de negociação no gerenciamento da dislexia é também evidenciado a partir de situaçôes em que a sua ausência é contestada. A falta do laudo médico acarreta entraves às famílias no acesso a suportes especiais, gerando posicionamentos da escola em relação à criança, como por exemplo, "ser tratada de igual para igual" (E3-M) ou "ficar sem matéria no caderno porque ele continuava sem conseguir copiar" (E20-M).

Cabe discutir que, anterior ao diagnóstico médico de "transtorno" de aprendizagem, tem lugar o diagnóstico da escola sobre o desempenho da criança, quando atesta a ruptura desta com suas normas organizativas do processo de aprendizagem. A arena de disputas e interesses e a dicotomia entre adoecimento e doença colocam em evidência a relação desigual entre o paciente e o médico e entre a família e a escola, fazendo com que o diagnóstico médico se converta em necessidade para acesso a direitos e serviços. A ausência de diagnóstico nega o acesso do paciente ao papel de doente e o reconhecimento institucional do sofrimento (JUTEL, 2009).

É sob esse prisma que o laudo, documento imprescindível no processo de negociaçáo do cuidado, torna-se objeto de disputa entre autoridades, e situase como elemento burocrático que emperra os processos de encaminhamento e acesso a diagnóstico e tratamento, seja ele médico ou escolar. Do ponto de vista do professor, "[ter laudo é] só uma questão burocrática [...] se o aluno tem o laudo, eu consigo encaminhá-lo para atendimento médico especializado, se o aluno não tem laudo, ele não precisa ser encaminhado" (E4-PE). Do ponto de vista da instituição escolar, o diagnóstico médico é central para os posicionamentos que a escola irá assumir: "Aí, a escola [...] falou assim: 'sem o diagnóstico [...] a gente não pode fazer nada”" (E7-PS). Do ponto de vista da instituição de saúde, o diagnóstico escolar é, por vezes, critério para admissão nos serviços diagnósticos: "pra levar pra $\mathrm{ABD}$ 
[Associação Brasileira de Dislexia] eu precisava de um laudo escolar. Aí [...] foi o ano inteiro de guerra, de briga" (E6-MD).

Enquanto categoria estigmatizante (GOFFMAN, 2004), porém dotada de valor social porquanto instituída pela autoridade médica, o diagnóstico confere aos pacientes uma identidade coletiva, que os remove do isolamento de seu sofrimento, fornecendo-lhes novas redes potenciais de apoio (JUTEL, 2009). Esse atributo comporta a sua função política de produzir movimentos de construção dessa identidade coletiva e de promover processos de reivindicação de necessidades de atenção em diferentes esferas sociais. Uma participante denuncia o sentimento de "desamparo" suscitado pela ausência do poder público quanto a posicionamentos mais efetivos para a abordagem das questôes evocadas pela dislexia - "há um abandono por parte da política pública [...] somos divididos em dois grupos, os normais [...] e os deficientes. Os transtornos, que é onde se encaixam esses déficits são totalmente desamparados" (E6-MD). Outra participante evoca o efeito que se abate sobre as famílias, diante da ausência do diagnóstico e da oferta de tratamento e suporte adequados a seus filhos - "a vida das famílias vira um inferno [...] a tristeza baixa naquela casa e a tristeza fica, porque não existe solução, e os pais [...] se atiram nas redes sociais numa forma de apoio" (E15-M).

A medicalização de diferentes processos da vida e a delimitação de um número cada vez maior de problemas no território da saúde-doença apontam para uma desarmonia com a fraca participação do Estado na oferta de mecanismos capazes de responder às novas demandas instauradas (JUTEL, 2009).

\section{Conclusões}

O diagnóstico e suas funçôes foram evocados nas narrativas de diferentes atores sociais sobre experiências relacionadas à dislexia, como a possibilidade de nomear e (res) significar experiências e favorecer processos de normalização da vida. Ao ser atestado através do laudo médico, adquiriu o estatuto de personagem principal. Assumiu diferentes significados e funçóes, positivas e negativas, pessoais e institucionais, e configurou-se como um "passaporte" para o reconhecimento e autorização da experiência de adoecimento pela dislexia em sua perspectiva de cronicidade.

O diagnóstico médico apoia a afirmação de identidades pessoais e a construção de identidades coletivas e é utilizado de forma valorosa para reclamar e assegurar o 
acesso a recursos e dispositivos de suporte e inclusão social. Por outro lado, expõe sua face negativa, como o poder da autoridade médica, o fenômeno da medicalização dos processos de desenvolvimento e de aprendizagem e a desarmonia com a participação do poder público.

A grande importância relacionada à busca pelo diagnóstico biomédico faz com que este seja aqui interpretado, pela sua força, como um "passaporte", uma autorização, que aponta para os múltiplos sentidos que este pode assumir em suas conexôes com elementos da cultura e das relaçôes de poder observadas no campo das interaçôes sociais e da estrutura social. ${ }^{1}$

\section{Referências}

ALVES, P. C. Itinerário terapêutico e os nexus de significados da doença. Politica \& Trabalho: Revista de Ciências Sociais, João Pessoa-PB, n. 42, p. 29-43, 2015.

BARSAGLINI, R. Adoecimentos crônicos, condiçôes crônicas, sofrimentos e fragilidades sociais: algumas reflexôes. In: CANESQUI, A. M. (Org.). Adoecimentos e sofrimentos de longa duração. São Paulo: Hucitec, 2013. p.70-103.

BRASIL. Projeto de Lei no 7.081-C, de 7 de abril de 2010. Dispóe sobre o diagnóstico e o tratamento da Dislexia e do Transtorno do Deficit de Atenção com Hiperatividade na educação básica. Brasília: Senado Federal, 2010. Disponível em: <http://www.camara.gov.br/sileg/ integras/1373328.pdf>. Acesso em: 20 jun. 2017.

CANESQUI, A. M. Adoecimentos e sofrimentos de longa duraçâo. $2^{\mathrm{a}}$ ed. São Paulo: Hucitec, 2015.

. Legitimidade e não legitimidade das experiências dos sofrimentos e adoecimentos de longa duração. Ciênc. Saúde Coletiva, v. 23, n. 2, p. 409-416, 2018.

CANGUILHEM, G. O normal e o patológico. $6^{\mathrm{a}} \mathrm{ed}$. Rio de Janeiro: Forense Universitária, 2009.

CAPRARA, A.; RODRIGUES, J. A relação assimétrica médico-paciente: repensando o vínculo terapêutico. Ciência \& Saúde Coletiva. Rio de Janeiro, v. 9, n. 1, p. 139-146, 2004.

CASTELLANOS, M. A narrativa nas pesquisas qualitativas em saúde. Ciência \& Saúde Coletiva, Rio de Janeiro, v. 19, n. 4, p. 1065-76, 2014.

. Adoecimento crônico infantil: um estudo das narrativas familiares. São Paulo: Hucitec/ Cesco, 2011.

CORSARO, W. A. Sociologia da Infância. 2a ed. Sáo Paulo: Penso, 2011.

DOCKRELL, J. et al. Supporting children with speech, language and communication needs: an overview of the results of the Better Communication Research Programme. International Journal of Language \& Communication Disorders. London-UK, v. 49, n. 5, p. 543-57, 2014. 
FLEISCHER, S.; FRANCH, M. Uma dor que não passa: aportes teórico-metodológicos de uma antropologia das doenças compridas. Politica \& Trabalho: Revista de Ciências Sociais, n. 42, p. 13-28, 2015.

GERHARDT, T. E. Itinerários terapêuticos em situaçóes de pobreza: diversidade e pluralidade. Cad. Saúde Pública. Rio de Janeiro, v. 22, n. 11, p. 2449-2463, 2006.

GOFFMAN, E. Estigma: notas sobre a manipulação da identidade deteriorada. Disponível em: <http://www.aberta.senad.gov.br/medias/original/201702/20170214-114707-001.pdf>. Acesso em: 15 set. 2017.

HARTSHORNE, M.; FREEMAN, K.; PARROTT, J. The Cost to the Nation of Children's Poor Communication. In: KERWIN-NYE, A. (Ed.) I Can Talk: series of reports exploring contemporary issues in children's speech, language and communication, London-UK, v. 2, 2006. Disponível em: <http://licensing.ican.org.uk/sites/licensing.ican.org.uk/files/Evidence/2_The_ Cost_to_the_Nation_of_Childrens_Poor_Communication.pdf>. Acesso em: 12 jun. 2017.

JOVCHELOVITCH, S.; BAUER, M. W. Entrevista narrativa. In: BAUER, M. W.; GASKELL G. (Eds.). Pesquisa qualitativa com texto, imagem e som: um manual prático. 2a ed. Petrópolis: Vozes, 2003. p. 90-113.

JUTEL, A. Classification, disease, and diagnosis. Perspectives in Biology and Medicine, Baltimore, Maryland, USA, v. 54, n. 2, p. 189-205, 2011.

. Sociology of diagnosis: a preliminary review. Sociology of Health \& Illness. OxfordUK, v. 31, n. 2, p. 278-99, 2009.

LAMEGO, D. T. C. Dimensóes sociopoliticas dosproblemas especificos de linguagem e aprendizagem: um estudo a partir de narrativas sobre a dislexia. Tese (Doutorado) - Instituto Nacional de Saúde da Mulher, da Criança e do Adolescente Fernandes Figueira, Rio de Janeiro, 2018.

LAW, J.; REILLY, S.; SNOW, P.C. Child speech, language and communication need reexamined in a public health context: a new direction for the speech and language therapy profession. International Journal of Language \& Communication Disorders. London-UK, v. 48, n. 5, p. 486-96, 2013.

LYON, G. R.; SHAYWITZ, S. E.; SHAYWITZ, B. A. A definition of dyslexia. Annals of Dyslexia, Baltimore, Maryland-USA, v. 53, n. 1, p. 1-14, 2003.

MINAYO, M. C. S. O desafio do conhecimento: pesquisa qualitativa em saúde. $14^{\mathrm{a}}$ ed. São Paulo: Hucitec, 2014.

MOREIRA, M. C. N. E quando a doença crônica é das crianças e adolescentes? Contribuiçóes sobre o artesanato de pesquisas sob a perspectiva da sociologia da infância e da juventude. In: CASTELlANOS, M. E. P. et al. (Orgs.). Cronicidade: experiência de adoecimento e cuidado sob a ótica das ciências sociais. Fortaleza: EdUECE, 2015. p. 125-55. 
MOREIRA, M. C. N. et al. Violence against children and adolescents with disabilities: narratives with guardianship councilors. Ciência \& Saúde Coletiva. Rio de Janeiro, v.19, n. 9, p. 3869-78, 2014.

MOREIRA, M. C. N.; CUNHA, C.; MELLO, A. Conversando sobre as crianças e os adolescentes com condiçôes crônicas complexas na atenção primária: a atenção domiciliar gerando interfaces entre as especialidades e o cuidado no domicílio. In: SANTOS, I. S.; GOLDSTEIN, R. A. (Orgs.). Rede de Pesquisa em Manguinhos: sociedade, gestores e pesquisadores em conexão com o SUS. São Paulo: Hucitec, 2016. p. 175-92.

MOREIRA, M. C. N.; MACEDO, A. D. de. A construção da subjetividade infantil a partir da vivência com o adoecimento: a questão do estigma. Arq. Bras. Psicol., v. 55, n. 1, 31-41, 2003.

MOREIRA, M. C. N.; SOUZA, W. S. A microssociologia de Erving Goffman e a análise relacional: um diálogo metodológico pela perspectiva das redes sociais na área de saúde. Teoria \&. Sociedade. Belo Horizonte, v. 9, n. 9, p. 38-61, 2002.

MORTATTI, R. L. Alfabetização no Brasil: conjecturas sobre as relaçôes entre políticas públicas e seus sujeitos privados. Revista Brasileira de Educação. Rio de Janeiro, v. 15, n. 44, 329-4, 2010. MOUSINHO, R. et al. Aquisição e desenvolvimento da Linguagem: dificuldades que podem surgir nesse percurso. Rev Psicopedagogia, São Paulo, v. 25, n. 78, p. 297-306, 2008.

MUYLAERT, C. J. et al. Entrevistas narrativas: um importante recurso em pesquisa qualitativa. Rev Esc Enferm USP, São Paulo, v. 48, n. 2, p. 193-9, 2014.

PEREIRA NETO, A. et al. O paciente informado e os saberes médicos: um estudo de etnografia virtual em comunidades de doentes no Facebook. História, Ciências, Saúde. Rio de Janeiro, v. 22, supl., p. 1653-71, 2015.

PROTUDJER, J. L. P. et al. Normalization strategies of children with asthma. Qualitative Health Research, v. 19, n. 1, p. 94-104, 2009.

ROSENBERG, C.E. The tyranny of diagnosis: specific entities and individual experience. The Milbank Quarterly. New York-USA, v. 80, n. 2, p. 237-60, 2002.

SAFATLE, V. O que é uma normatividade vital? Saúde e doença a partir de Georges Canguilhem. Scientice Studia. São Paulo, v. 9, n. 1, p. 11-27, 2011.

SANTOS, M. T. M.; NAVAS, A. L. G. P. Transtornos de linguagem escrita: teoria e prática. Barueri: Manole, 2016.

SÃO BENTO, P. A. S. Vozes de Fênix: narrativas de mulheres que se associam a partir da experiência com endometriose (Tese) - Instituto Nacional de Saúde da Mulher, da Criança e do Adolescente Fernandes Figueira, Rio de Janeiro, 2016.

THOMPSON, J. B. Ideologia e cultura moderna: teoria social crítica na era dos meios de comunicação de massa. 8a ed. Petrópolis: Vozes, 2009. 
VELHO, G. Observando o familiar. In: . (Org.). Individualismo e cultura: notas para uma antropologia da sociedade contemporânea. Rio de Janeiro: Zahar, 1978. p. 123-132.

WILLIAMS, B. et al. "I've never not had it so I don't really know what it's like not to": nondifference and biographical disruption among children and young people with Cystic Fibrosis. Qualitative Health Research; v. 19, n. 10, p. 1443-55, 2009.

\section{Nota}

${ }^{1}$ D. T. C. Lamego realizou a pesquisa de campo, análise dos resultados, redação e revisão final do artigo. M. C. N. Moreira orientou a pesquisa e participou da redação e revisão final do artigo. 


\section{Abstract}

Diagnosis as a "passport" for recognition and significance of experiences in dyslexia

We analyze the implications of the diagnosis of dyslexia in the production of meanings about the experiences related to this condition, from the perspective of different social actors in different fields of interactions. We used the narratives method in dialogue with the concepts of "normality" and "pathology", "ideology" and "culture" and with the theoretical-conceptual field of "Sociology of Diagnosis". We conducted 19 narrative interviews with social actors differently positioned in the social structure, recruited from the social network Facebook, in the group "Dyslexia and Parents". We discussed the socio-historical context of social construction of the diagnostic category "dyslexia"; the pilgrimage by diagnosis, the barriers and conflicts found in the health and education systems; the importance of the biomedical diagnosis for the significance of the experience of illness by dyslexia; the role and functions of the diagnosis of dyslexia for the construction of identity marks, as well as for the search for repositioning and reordering of the daily life and for the recognition and access to rights in public spaces. The diagnosis of dyslexia was interpreted as a main character that presents positive and negative functions in the daily life of people living with this condition.

> Keywords: dyslexia; diagnosis; sociology of diagnosis, narratives. 